\title{
Neuro-Cognitive Dysfunction In Substance Abusers - A Hospital Based Study
}

\author{
Chaudhary Rupesh Kumar ${ }^{1}$, Pankaj Kumar², Mishra Bholeshwar Prasad ${ }^{3}$ \\ ${ }^{1}$ Associate Professor, Department of Psychiatry, Dayanand Medical College \& Hospital, Tagore Nagar, Civil Lines, \\ Ludhiana-141001, Punjab, India. \\ ${ }^{2}$ Assistant Professor, Department of Psychiatry, Dayanand Medical College \& Hospital, Tagore Nagar, Civil Lines, \\ Ludhiana-141001, Punjab, India. \\ ${ }^{3}$ Professor (Clinical Psychology), Department of Psychiatry, Dayanand Medical College \& Hospital, Tagore Nagar, \\ Civil Lines, Ludhiana-141001, Punjab, India. \\ Email: rupeshchaudhry123@yahoo.co.in
}

\begin{abstract}
Background: The brain region and neural processes that underlie addiction overlap extensively with those that support cognitive functioning, including learning, memory and reasoning. Cocaine and opioids cause deficit in cognitive flexibility, amphetamines causes deficits in attention and impulse control; alcohol and nicotine causes deficit in working memory and attention. The present study was planned to understand harmful effects of substance use on neuropsychological functioning of the patients with substance dependence.

Methodology: The study was conducted at Dayanand Medical College and Hospital, Ludhiana, India. A total of 30 known substance dependent patients (diagnosed as per ICD 10 criteria), both indoor as well as outdoor were evaluated for their intellectual and memory functioning using Wechsler intelligence test (verbal, Indian version which has 4 subtests ie information, digit span, arithmetic and comprehension), Alexander's Pass Along Test (to see executive function) and PGI memory test (Indian version of Wechsler memory test) and then the results were compared with the control group. Patients with any other medical disorder, head injury, seizure disorder and any pre-morbid psychiatric problem were excluded from the study.

Results: The protocol shows that majority of patients show significant deficit in comprehension parameters of verbal intelligence and arithmetic ability. The protocol also reflects that the patients have impairment in delayed recall and recognition of visual stimuli.

Conclusion: The study found that drug related cognitive changes may bias patients towards response and action that contributes to the cycle of addiction and also hinder patient's ability to benefit from counseling.
\end{abstract}

Key Words: Substance abuse, Neuro-cognitive dysfunction, opioids, cannabis.

(Paper received $-6^{\text {th }}$ January 2017, Peer review completed $-4^{\text {th }}$ March 2017, Accepted $-6^{\text {th }}$ March 2017)

\section{INTRODUCTION}

Chronic use of psychoactive substances is associated with widespread deficits in neuropsychological function [1-2]. These deficits are pronounced in the executive domains including decision making, response inhibition, verbal learning and memory [3-4]. These deficits may be associated with prefrontal cortex dysfunction and their extent and nature is likely to depend upon the substance of abuse. The prevalence of cognitive impairments in substance abusers varies from 30-80 \% [5-6]. Cognitive impairment in such patients leads to poorer treatment outcomes including decreased treatment retention [7-8]., lower self efficacy, decreased insight into the illness, greater reflection impulsivity [9]. In addition, cognitive 
impairment among alcoholics has a negative impact on drink refusal skill acquisition and aftercare treatment attendance [10].

Unfortunately, neuropsychological assessment is typically not an aspect of patient evaluation in substance abuse treatment programme because it is time and resource consuming. Secondly, the cognitive impairment cannot be adequately identified by drug counsellors in a clinical impression or through self respect. The present study was planned to understand harmful effects of substance use on neuropsychological functioning of the patients with substance dependence.

\section{METHODOLOGY}

The study was conducted at Dayanand Medical College and Hospital, Ludhiana, India. A total of 30 known substance dependent patients (diagnosed as per ICD 10 criteria) were taken for the study after obtaining an informed consent for the same. Both indoor as well as outdoor patients were evaluated for their intellectual and memory functioning using Wechsler intelligence test [11] (verbal, Indian version which has 4 subtests ie information, digit span, arithmetic and comprehension), Alexander's Pass Along Test [12] (to see executive function) and PGI memory test [13] (Indian version of Wechsler memory test) and then the results were compared with the control group. Patients with any other medical disorder, head injury, seizure disorder and any premorbid psychiatric problem were excluded from the study.

\section{STATISTICAL ANALYSIS}

Basic descriptive statistics and percentages were used in the summation and analysis of results.

\section{RESULTS}

Table 1 shows the sample of the present study with most of the patients were in the age group of 21-40 and were mostly educated up to matriculate level.

Table 1

\begin{tabular}{|cc|}
\hline Factor & $\mathbf{( N = 3 0 )}$ \\
\hline Age (In years) & \\
\hline$<20$ years & 06 \\
\hline $21-40$ years & 20 \\
\hline$>41$ years & 04 \\
\hline Education level \\
\hline $10^{\text {th }}$ standard & 20 \\
\hline Graduation & 06 \\
\hline Post Graduation & 04 \\
\hline
\end{tabular}

Table 2 shows verbal and non verbal intellectual functioning of subjects on verbal intelligence test and Alexander pass along test. $80 \%$ of the subjects on comprehension and $66.67 \%$ of the subjects on arithmetic subscales were showing deficit. On attention and concentration parameters i.e. digit span test $66.67 \%$ of subjects were showing significant deficit. On executive function parameter (Alexander pass along test) significant deficit $(93.33 \%)$ was noticed among the subjects.

Table 3 shows the memory functioning of the subjects. Remote memory (73.33\%) and recent memory (86.67\%) appear highly affected areas. Delayed recall (76.6\%) and immediate recall (80\%) are the other areas significantly affected in the subjects. 
Table 2 - Performance of subjects on Wechsler intelligence test \& Alexander's Pass Along Test

\begin{tabular}{|cccccc|}
\hline & $\begin{array}{c}\text { Mild } \\
\mathbf{( 5 0 - 7 0 )}\end{array}$ & $\begin{array}{c}\text { Moderate } \\
\mathbf{( 3 5}-\mathbf{4 9 )}\end{array}$ & $\begin{array}{c}\text { Severe } \\
\mathbf{( 2 0}-\mathbf{3 4})\end{array}$ & Normal & $\begin{array}{c}\text { Total } \\
\mathbf{( \% )}\end{array}$ \\
\hline Information & 10 & 02 & 02 & 16 & 46.67 \\
\hline Comprehension & 12 & 10 & 02 & 06 & 80 \\
\hline Arithmetic & 12 & 04 & 04 & 10 & 66.67 \\
\hline Digit Span & 10 & 06 & 04 & 10 & 66.67 \\
\hline Performance IQ & 26 & 00 & 02 & 02 & 93.33 \\
\hline
\end{tabular}

Table 3 - Performance of participants on the PGI Memory Test

\begin{tabular}{|ccccc|}
\hline Items & Normal & Mild & Severe & Total ( \%) \\
\hline Remote Memory & 08 & 16 & 06 & 73.33 \\
\hline Recent Memory & 04 & 18 & 08 & 86.67 \\
\hline Mental Balance & 15 & 10 & 05 & 50 \\
\hline $\begin{array}{c}\text { Attention and } \\
\text { Concentration }\end{array}$ & 10 & 15 & 05 & 66.67 \\
\hline Delayed Recall & 07 & 20 & 03 & 76.66 \\
\hline Immediate Recall & 06 & 14 & 10 & 80 \\
\hline $\begin{array}{c}\text { Verbal Retention } \\
\text { (Similar Pairs) }\end{array}$ & 10 & 15 & 05 & 66.66 \\
\hline $\begin{array}{c}\text { Verbal Retention } \\
\text { (Dissimilar Pairs) }\end{array}$ & 12 & 10 & 08 & 60 \\
\hline Visual Retention & 08 & 17 & 05 & 73.3 \\
\hline Recognition & 22 & 07 & 01 & 26.67 \\
\hline
\end{tabular}

DISCUSSION

The protocol shows that majority of patients show significant deficit in comprehension and arithmetic ability parameters of verbal intelligence. This is in accordance with the findings of the research which have also concluded that chronic abuse of substances like cocaine, opioids \& alcohol result in excessive cognitive alteration in many individuals [14-15]. Long-term cannabis users have impaired learning, retention, and retrieval of dictated words, and both long-term and short-term users show deficits in time estimation [16]. The present study reflects that the patients were showing difficulty in new learning and recall as well as they fail to apply new skills, difficulty in abstract thinking, inflexible cognition and difficulty in changing the mental set. These findings were reported in the literature [17]. Chronic amphetamine and heroin users show a deficits in a range of cognitive skills, including verbal fluency, pattern recognition, planning, and the ability to shift attention from one frame of reference to another [18]. Studies have shown that morphine slightly impaired both sexes' performance on a test of working memory in which they were asked to repeat a set of digits in reverse order [19] which is in concordance with the results of our study.

The protocol also reflects that the patients have impairments in all the parameters of memory testing as remote, recent \& immediate recall. There is marked impairment of visual retention $(73.3 \%) \&$ verbal retention of similar pairs (66.6\%). Studies have shown that Cognitive functions including decision making, attention, working memory, inhibitory control, planning, fluency, reasoning, and processing speed are all 
negatively impacted with drug use [20-23]. This is in concordance with the present study which has shows the deficits in executive functions of substance abusers. The similar findings were generated in the present study when PGI memory test \& Wechsler's tests were applied.

Drug related cognitive changes may bias patients towards response and action that contributes to the cycle of addiction and also hinder patient's ability to benefit from counselling. More sessions and reminders may be necessary for these patients in incorporating abstinence - sustaining strategies into their daily routine. Developing and testing a modified treatment to match the abilities of impaired patients. Developing a cognitively friendly treatment for drug abuse patients to be offered broadly with the flexibility for quick advancement is also deemed helpful. This level approach to treatment would be useful in bypassing the problems associated with neuropsychological testing in treatment settings, and developing a brief screening measure with sensitivity to aid in identification of cognitive deficits [24]. Testing if and how treatments for cognitively impaired drug abusers can be transported to the community, including how to train treatment providers. Examining mediation and moderation relationships between impairment and intrapersonal capabilities such as psychopathology and medical status, change processes such as self-efficacy and motivation, and environmental factors such as social support. Improving coping skills strategies for adolescents with poor neurocognitive abilities would also benefit. Understanding how these abnormalities are related and their role in drug abuse could potentially contribute to the development of more appropriately targeted treatment interventions [25].

\section{REFERENCES}

1. Rogers RD, Robbins TW. Investigating the neurocognitive deficits associated with chronic drug misuse. Curr Opin Neurobiol 2001;11(2):250-7.

2. Verdejo-García A, López-Torrecillas F, Giménez CO, Pérez-García M. Clinical implications and methodological challenges in the study of the neuropsychological correlates of cannabis, stimulant, and opioid abuse. Neuropsychol Rev 2004;14(1):1-41.

3. Verdejo-García A, Bechara A, Recknor EC, Perez-Garcia M. Executive dysfunction in substance dependent individuals during drug use and abstinence: an examination of the behavioral, cognitive and emotional correlates of addiction. J Int Neuropsychol Soc 2006;12(03):405-15.

4. Mintzer MZ, Stitzer ML. Cognitive impairment in methadone maintenance patients. Drug Alcohol Depend 2002;67(1):41-51.

5. Nordahl TE, Salo R, Leamon M. Neuropsychological effects of chronic methamphetamine use on neurotransmitters and cognition: a review. J Neuropsychiatr Clin Neurosci 2003;15(3):317-25.

6. Wiers RW, Stacy AW. Implicit cognition and addiction. Curr Dir Psychol Sci 2006;15(6):292-6.

7. Wiers RW, Stacy AW. Handbook of implicit cognition and addiction. Sage; 2006.

8. Bates ME, Pawlak AP, Tonigan JS, Buckman JF. Cognitive impairment influences drinking outcome by altering therapeutic mechanisms of change. Psychol Addict Behav 2006;20(3):241-53.

9. Copersino ML, Fals-Stewart W, Fitzmaurice G, Schretlen DJ, Sokoloff J, Weiss RD. Rapid cognitive screening of patients with substance use disorders. Exp Clin Psychopharmacol 2009;17(5):337-44.

10. Smith DE, McCrady BS. Cognitive impairment among alcoholics: Impact on drink refusal skill acquisition and treatment outcome. Addict Behav 1991;16(5):265-74.

11. Wechsler D. WAIS-III: Wechsler adult intelligence scale. San Antonio, TX: Psychological Corporation; 1997.

12. Alexander WP. A new performance test of intelligence. Br J Psychology 1932;23(1):52-63.

13. Krishnadas R, Moore BP, Nayak A, Patel RR. Relationship of cognitive function in patients with schizophrenia in remission to disability: a cross-sectional study in an Indian sample. Ann Gen Psychiatry 2007;6(1):19-26.

14. Fernández-Serrano MJ, Pérez-García M, Schmidt Río-Valle J, Verdejo-García A. Neuropsychological consequences of alcohol and drug abuse on different components of executive functions. J Psychopharmacol 2010;24(9):1317-32.

15. Solowij N, Stephens RS, Roffman RA, Babor T, Kadden R, Miller M, Christiansen K, McRee B, Vendetti J. Cognitive functioning of long-term heavy cannabis users seeking treatment. JAMA 2002;287(9):1123-31.

16. Solowij N, Grenyer BF. Are the adverse consequences of cannabis use age-dependent?. Addiction 2002;97(9):1083-6. 
17. Ornstein TJ, Iddon JL, Baldacchino AM, Sahakian BJ, London M, Everitt BJ, Robbins TW. Profiles of cognitive dysfunction in chronic amphetamine and heroin abusers. Neuropsychopharmacology 2000;23(2):113-26.

18. Friswell J, Phillips C, Holding J, Morgan CJ, Brandner B, Curran HV. Acute effects of opioids on memory functions of healthy men and women. Psychopharmacology 2008;198(2):243-50.

19. Lundqvist T. Cognitive consequences of cannabis use: comparison with abuse of stimulants and heroin with regard to attention, memory and executive functions. Pharmacol Biochem Behav 2005;81(2):319-30.

20. Quednow BB, Jessen F, Kühn KU, Maier W, Daum I, Wagner M. Memory deficits in abstinent MDMA (ecstasy) users: neuropsychological evidence of frontal dysfunction. J Psychopharmacol 2006;20(3):373-84.

21. Lamers CT, Bechara A, Rizzo M, Ramaekers JG. Cognitive function and mood in MDMA/THC users, THC users and non-drug using controls. J Psychopharmacol 2006;20(2):302-11.

22. Malmberg M, Overbeek G, Monshouwer K, Lammers J, Vollebergh WA, Engels RC. Substance use risk profiles and associations with early substance use in adolescence. J Behav Med 2010;33(6):474-85.

23. Vik PW, Cellucci T, Jarchow A, Hedt J. Cognitive impairment in substance abuse. Psychiatr Clin North Am 2004;27(1):97-109.

24. Rooke SE, Hine DW, Thorsteinsson EB. Implicit cognition and substance use: a meta-analysis. Addict Behav 2008;33(10):1314-28.

25. Grenard JL, Ames SL, Wiers RW, Thush C, Sussman S, Stacy AW. Working memory capacity moderates the predictive effects of drug-related associations on substance use. Psychol Addict Behav 2008;22(3):426-33.

$* * * * * * * * * * * * * * * * * * * * * * * * * * *$

Acknowledgements - Nil

Source of Funding - Nil

Conflict of Interest $-\mathrm{Nil}$ 